Mini-Review

\title{
Suggestion of an alternative approach of inhalation of volatile chemicals from onion and garlic for isolated patient of mild onset infected Flu: Review and communication
}

\author{
${ }^{1,3}$ Huibing Tan*, ${ }^{2}$ Ganqiu Wu, ${ }^{3}$ Xiaotong Li, ${ }^{3}$ Wei Hou \\ ${ }^{1}$ Laboratory of Biological Enzyme, Qinhuangdao Yier Bio-tech Co. LTD., Qinghuangdao, Hebei, \\ 06000, China, \\ ${ }^{2}$ Department of histology and embryology, Xiangya medical college, Central South University, \\ Changsha, Hunan, 410013, China \\ ${ }^{3}$ Department of Anatomy, Jinzhou Medical University, Jinzhou, Liaoning 121001, China
}

Abstract

Virus-infected Flu is a common disease. To date, no specific drugs are available to manage the symptoms of cough, headache and sputum production. An alternative Chinese herb medicine is introduced for virus-infected Flu or similar infection. Before hospitalization, some of patients may scare for cross-infection with mild symptoms or hardly go to hospital if encountered a temporary lockdown or quarantine. Some Chinese practice self-treatment of cough, headache and sputum production by inhalation of volatile chemicals from onion and garlic. Author used to take the same alternative approach of inhalation of onion, garlic or scallions for self-treatment when suffered virus caused flu with cough, headache and sputum production at onset disease. In this article, the biomedical effects of onion and garlic are reviewed. To help patients with mild symptoms of virus infected Flu, a simple home-based treatment was suggested to self-treatment because of temporary isolation and hardly going to hospitalization. The alternative approach may also suggest for some mild virus infected respiratory diseases caused by virus at onset disease.

Keywords: mild virus-infected flu, home-based treatment, inhalation of volatile chemicals, onion, garlic

\section{* Correspondence:}

Huibing Tan M.D., Ph.D., Laboratory of Biological Enzyme, Qinhuangdao Yier Bio-tech Co. LTD., Qinghuangdao, Hebei, 06000, China. davidtanhb@foxmail.com 
Inhalation for therapeutic vapors and aerosols has been used over thousands of years in various cultures[1]. Inhabitants are used to treat pneumonia[2]. The treatment usually needs commercialized device for the controlled inhalation of therapeutic aerosols. In some special situation, patient has to treat him or her-self for out-of-hospital treatment. Recently, outbreak of a novel coronavirus (2019nCoV)-infected pneumonia has occurred in Wuhan, China, since December 2019. World-wide human-to-human transmission of coronavirus also become global health concern[3]. China government made effort to prevent panic[4]. However, the panic situation of disease outbreak is still a problem in the cities and rural areas, because of lack of remedy and hospitalization especially at very beginning[5]. To date, "the death toll from the coronavirus topped 1,000 on Monday, as more than 42,000 cases are confirmed across the globe" according to CBS News[6]. Some information is updated according to IFENG NEWS [7]. Nonpharmaceutical Interventions of the disease are still a great challenge for the present situation[8]. Repurposing host-based therapeutics are suggested for control coronavirus and influenza virus[9, 10]. However, it still takes time to find effective drugs for 2019-nCoV infected pneumonia. Besides severe acute respiratory infections, many patients with mild symptoms could be treated in home care condition with doctor's suggestion. However, doctor may not be available for every patient for the outbreak situation. Some patients have to strand in home with no choice. Respiratory symptoms at onset of illness were cough $76 \%$ and sputum production $28 \%$ [11]. For home cared patients, some of them alternatively use self-managed treatment. Before the development of effective treatment, some potential alternative medication may be considered for some symptoms.

Onion[12-18], garlic[19-21] and scallions[22, 23] are usually some ready-to-use therapeutic food. Both of garlic and onion extracts are found of therapeutic properties including antimicrobial, antiviral, antifungal, anti-protozoal, hepatoprotective, cardioprotective, anti-inflammatory, neuroprotective, anti-amnesic, anticarcinogenic, antimutagenic, antiasthmatic, immunomodulatory, hypolipidemic, anti-hypertensive, anti-diabetic and antioxidant[24]. Garlic and onion are used as natural remedies for the relief of Cold and Flu Symptoms[25, 26]. Extracts of onions show the antiviral effects of against avian influenza virus subtype H9N2[27]. Allium sativum[28] shows a better antiviral effect than that of allium cepa (onion)[29]. As mention above, therapeutic aerosol delivery is still a potential approach for drug delivery and administration. Onion, garlic and scallion have strong volatile compounds, which could be applied for therapeutic inhalation. The pharmacology and physiology of onion are also studied in China[30-36]. That is why we hypothesized that inhalation of onion for the $2019-\mathrm{nCoV}$ pneumonia.

Compared with other route of administration, the therapeutic inhalation may be beneficial allergy or toxic (some situations see following demonstration). "The primary goal of inhalation therapy for local treatment is to reduce pulmonary symptoms, for example, through the alleviation and/or prevention of airway inflammation and constriction" $[37,38]$. The pathological lesion of 2019-nCoV pneumonia locates in the lung tissues. Volatile biochemicals may act more efficient to inhibit virus or bacterial in the lung tissue because it directly targeted the virus, bacteria and pathological tissues when intake of the volatile biochemicals through the air-blood barrier.

In the special case of temporary the lockdown or quarantine in Wuhan and other cities, the 
isolation for the 2019-nCoV is kept some patients away from hospitalization for normal treatment. Most importantly, it may help to reduce cross-infection for home care treatment of normal flu patients. However, patients still need treatment to relieve their symptoms. The therapeutic inhalation also helped some patients of mild symptom to relief of panic symptoms if the normal remedy was lack. The therapeutic inhalation of onion or garlic was potential for adjuvant therapy.

Huibing Tan has tried an alternative approach for home care of mild respiratory symptoms when suffered virus-flu before. The approach helped to relief headache, cough, sputum production and sneeze. For better experience, it was better to perform the self-management of the approach at onset of the disease. The inhalation of onion or garlic helped to ameliorate the symptoms of flu. It was an alternative out-of-hospital treatment. No other side effects were found. We also suggested that eating of fresh prepared food of onion, garlic and scallions benefited human immunity.
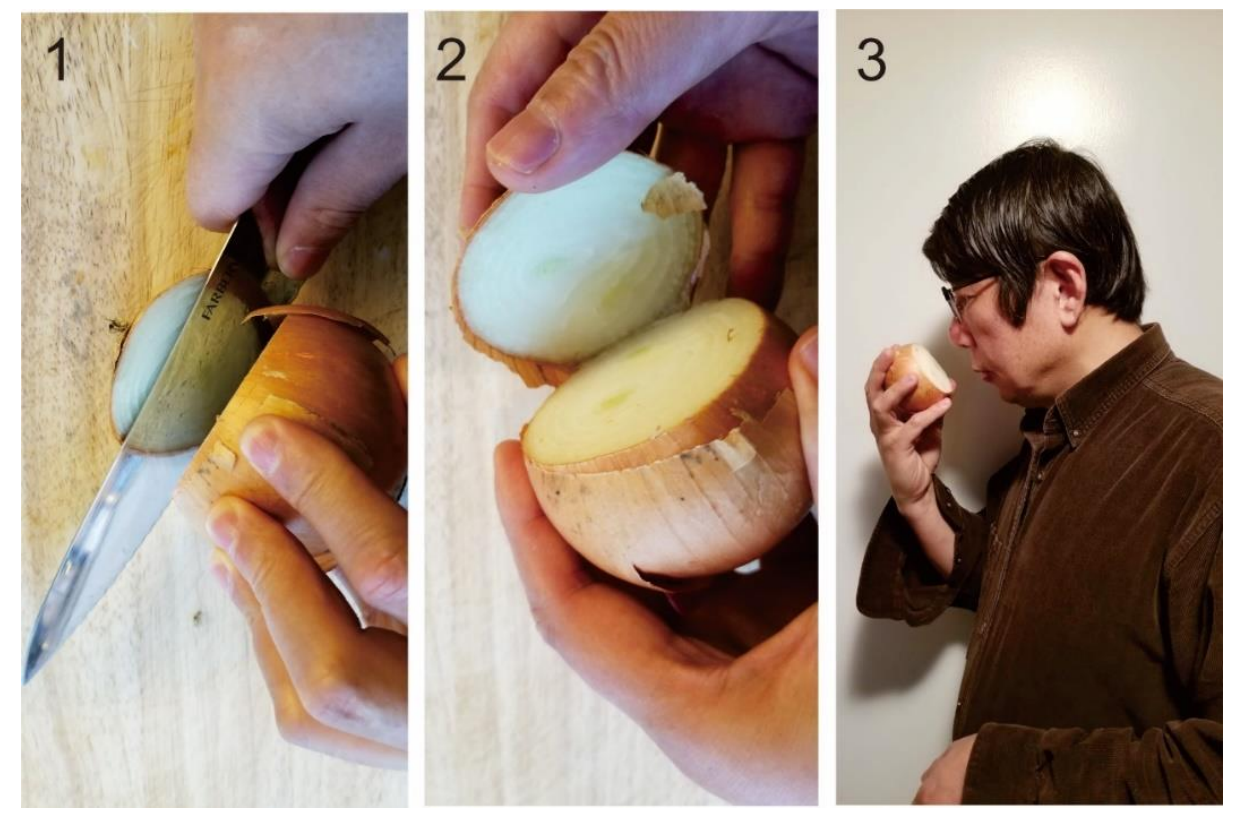

Figure 1. Preparation of onion for inhalation. Cut off one fourth or one fifth of onion, and put the big part of the onion under patient's nose. Deeply inhaled through the nose, held breath for 1-2 seconds, exhaled naturally through mouth. Doration of inhalation for 1-5 min each time. How many times a day is depended on selfjudgment. Cut deep layer for further use if the odor reduced.

Direct inhalation of the fresh onion was easy to practice without need any other therapeutic equipment. It could apply to any one who eat onion, garlic and or scallions without allergy of those foods. The concentration of chemicals varies in the different color of onions[17]. For example, some of yellow onions and red onions contain more quercetin[17]. Figure 1 showed a simple way to prepare onion for inhalation. For better action, patients could also blend of onion or cut it into pieces, put blended onion into a glass or a suitable container, and inhaled the onion odor with the container. The Figure 1 showed an easy and straightforward way to get the treatment. The patients could try garlic and or scallions if the onion was not available. Patient should self-adjust the duration of the inhalation. Stop the continued inhalation if the odor of onion produced strong irritating stimulation of the respiratory tract. Patient should carefully prevent respiratory alkalosis caused by 
hyperventilation.

Similarly, minced garlic may also be prepared for the same self -treatment at onset of the virusinfected disease. Qiugan Wu recommends by putting minced garlic into mask to prevent virus transmission or treat of the symptoms of virus-infected disease[39]. In 1956, Zhao suggests that garlic is used to treat common Flu [40]. Abdullah also recommends Echinacea-garlic is used as a strategic call for flu season[41]. Garlic extract benefits human immunity[42, 43]. Ma suggests that preparation of garlic medical plaster on acupoints treats common Flu[44]. Wang et al suggest that garlic and scallions can be used to treat the common Flu[45].

Food hypersensitivity of garlic or onion indicates a prevalence of $2.92 \%[46]$. Oral administration of onion can cause toxic in dogs[34]. At present, no clinical studies reported about the inhalation of onion, garlic and or scallions to treat 2019-nCoV pneumonia. we suggested that it was better to ask doctor for advices or set a skin test for allergic examination before inhalation of the onion, garlic and or scallions. The inhalation of the onion, garlic and or scallions was not a standard clinical treatment. The alternative approach may also suggest for common flu with cough or sputum production as well as other respiratory diseases caused by virus. To further confirmation, the relevant experiments or clinical trial should be considered in future. Author do not suggest patients to try other chemical or compounds by the similar ways. The clean, good quality and healthy onion, garlic or scallions could be used without any other chemical contamination. It was better to perform for mild symptoms or onset of the disease.

Funding: This work received no external funding.

Conflict of interests

The authors have no conflicts of interest to declare.

\section{Reference:}

[1] S.W. Stein, C.G. Thiel, The history of therapeutic aerosols: a chronological review, Journal of aerosol medicine and pulmonary drug delivery, 30 (2017) 20-41.

[2] d.M.R. Malo, E. Mortensen, M. Restrepo, L. Copeland, M. Pugh, A. Anzueto, Inhaled corticosteroid use is associated with lower mortality for subjects with COPD and hospitalised with pneumonia, The European respiratory journal, 36 (2010) 751.

[3] L.T. Phan, T.V. Nguyen, Q.C. Luong, T.V. Nguyen, H.T. Nguyen, H.Q. Le, T.T. Nguyen, T.M. Cao, Q.D. Pham, Importation and human-to-human transmission of a novel coronavirus in Vietnam, New England Journal of Medicine, (2020).

[4] Z. Zhouxiang, Transparency prevents panic in virus case, Chinadaily.com.cn, (2020, Jan 7).

[5] 张文宏, 恐慌与激情过后: 以理性与科学抗击新型冠状病毒, 微生物与感染, 15 (2020) 1-4.

[6] The death toll from the coronavirus topped 1,000 on Monday, as more than 42,000 cases were confirmed across the globe., CBS News, (2020, February 10).

[7] 新冠肺炎 NCP 疫情实时动态, IFENG News, (2020, February 10).

[8] A.L. Phelan, R. Katz, L.O. Gostin, The Novel Coronavirus Originating in Wuhan, China: Challenges for 
Global Health Governance, Jama, (2020).

[9] C.-C. Li, X.-J. Wang, H.-C.R. Wang, Repurposing host-based therapeutics to control coronavirus and influenza virus, Drug discovery today, (2019).

[10] Y. Zhou, Y. Hou, J. Shen, Y. Huang, W. Martin, F. Cheng, Network-based Drug Repurposing for Human Coronavirus, medRxiv, DOI 10.1101/2020.02.03.20020263(2020) 2020.2002.2003.20020263.

[11] C. Huang, Y. Wang, X. Li, L. Ren, J. Zhao, Y. Hu, L. Zhang, G. Fan, J. Xu, X. Gu, Z. Cheng, T. Yu, J. Xia, Y. Wei, W. Wu, X. Xie, W. Yin, H. Li, M. Liu, Y. Xiao, H. Gao, L. Guo, J. Xie, G. Wang, R. Jiang, Z. Gao, Q. Jin, J. Wang, B. Cao, Clinical features of patients infected with 2019 novel coronavirus in Wuhan, China, The Lancet, DOI https://doi.org/10.1016/S0140-6736(20)30183-5(2020).

[12] J.F. Carson, Chemistry and biological properties of onions and garlic, Food Reviews International, 3 (1987) 71-103.

[13] M. Corzo-Martínez, N. Corzo, M. Villamiel, Biological properties of onions and garlic, Trends in food science \& technology, 18 (2007) 609-625.

[14] M. Goodarzi, N. Landy, S. Nanekarani, Effect of onion (Allium cepa L.) as an antibiotic growth promoter substitution on performance, immune responses and serum biochemical parameters in broiler chicks, Health, 5 (2013) 1210.

[15] J.-B. Lee, S. Miyake, R. Umetsu, K. Hayashi, T. Chijimatsu, T. Hayashi, Anti-influenza A virus effects of fructan from Welsh onion (Allium fistulosum L.), Food chemistry, 134 (2012) 2164-2168.

[16] E. Mohamed, Antiviral properties of garlic cloves juice compared with onion bulbs juice against potato virus Y (PVY), J. Am. Sci, 6 (2010) 302-310.

[17] B.S. Patil, L.M. Pike, K.S. Yoo, Variation in the quercetin content in different colored onions (Allium cepa L.), Journal of the American Society for Horticultural Science, 120 (1995) 909-913.

[18] H. Ueda, A. Takeuchi, T. Wako, Activation of immune responses in mice by an oral administration of bunching onion (Allium fistulosum) mucus, Bioscience, biotechnology, and biochemistry, 77 (2013) 1809-1813.

[19] G. Gebreyohannes, M. Gebreyohannes, Medicinal values of garlic: A review, International Journal of Medicine and Medical Sciences, 5 (2013) 401-408.

[20] J.C. Harris, S. Cottrell, S. Plummer, D. Lloyd, Antimicrobial properties of Allium sativum (garlic), Applied Microbiology and Biotechnology, 57 (2001) 282-286.

[21] B.G. Hughes, L.D. Lawson, Antimicrobial effects of Allium sativum L.(garlic), Allium ampeloprasum L.(elephant garlic), and Allium cepa L.(onion), garlic compounds and commercial garlic supplement products, Phytotherapy Research, 5 (1991) 154-158.

[22] A.-M. Le Bon, M.-H. Siess, Organosulfur compounds from Allium and the chemoprevention of cancer, Drug metabolism and drug interactions, 17 (2000) 51-80.

[23] K.H. Kyung, Y.C. Lee, ANTIMICROBIAL ACTIVITIES OF SULFUR COMPOUNDS DERIVED FROM S-ALK (EN) YL-L-CYSTEINE SULFOXIDES IN ALLIUM AND BRASSICA, Food Reviews International, 17 (2001) 183 198.

[24] P. S Bisen, M. Emerald, Nutritional and therapeutic potential of garlic and onion (Allium sp.), Current Nutrition \& Food Science, 12 (2016) 190-199.

[25] C.I. Wright, Natural Remedies for the Relief of Cold and Flu Symptoms: The Evidence for Garlic, Onion, Chilli and Chocolate, J. Homeopath. Ayurvedic Med, 4 (2015) 10-13.

[26] A. Raal, D. Volmer, R. Soukand, S. Hratkevitš, R. Kalle, Complementary treatment of the common cold and flu with medicinal plants-results from two samples of pharmacy customers in Estonia, PloS one, 8 (2013). 
[27] S. Ahmadi, Z. Rajabi, M.V. Marandi, Evaluation of the antiviral effects of aqueous extracts of red and yellow onions (Allium Cepa) against avian influenza virus subtype H9N2, virus, 8 (2018) 10.

[28] M. Bociaga-Jasik, A. Polus, J. Goralska, U. Razny, D. Siedlecka, B. Zapala, R. Chrzan, A. Garlicki, T. Mach, A. Dembinska-Kiec, Impact of antiretroviral therapy on selected metabolic disorders - pilot study, Adv Clin Exp Med, 23 (2014) 539-549.

[29] R.M. Romeilah, S.A. Fayed, G.I. Mahmoud, Chemical compositions, antiviral and antioxidant activities of seven essential oils, Journal of Applied Sciences Research, 6 (2010) 50-62.

[30] 张媛柯，田荣波，张芳，徐川微，杨茂静，洋葱研究进展，实用中医药杂志，(2010) 591-592.

[31] 从英珍, 王志军, 食洋葱治疗高血脂, 医学理论与实践, 2004,7.

[32] 耿凤琴，陈立东，洋葱治疗动物疾病，畜牧兽医科技信息，(1996) 8-9.

[33] 桂蜀華, 蔣東旭，袁捷，葉其馨，洋葱不同提取物抗真菌活性研究，廣州中醫藥大學學報，22 (2005) 379-382.

[34] 李生涛, 两例犬洋葱中毒的诊断与治疗, 中兽医学杂志, (2016) 56-57.

[35] 徐大勇, 韦汉群, 张文丽, 洋葱对草鱼细菌性烂鳃病的治疗效果试验, 安徽農業科學, 36 (2008) 6338-6339.

[36] 许立功, 洋葱治疗糖尿病的研究, 广西医学, (1976) 40.

[37] J.M. Borghardt, C. Kloft, A. Sharma, Inhaled Therapy in Respiratory Disease: The Complex Interplay of Pulmonary Kinetic Processes, Canadian respiratory journal, 2018 (2018) 2732017.

[38] A. D'Urzo, K.R. Chapman, J.F. Donohue, P. Kardos, M.R. Maleki-Yazdi, D. Price, Inhaler Devices for Delivery of LABA/LAMA Fixed-Dose Combinations in Patients with COPD, Pulmonary therapy, 5 (2019) 23-41.

[39] Wugq, 基于口罩的大蒜素吸入疗法或可防治新冠肺炎，美篇， https://www.meipian5.cn/2p1a252i?share depth=3\&user id=ohbslul76j4IS34E8PIT2NFj5awI\&sharer id=ojq1ttxupfkUEGFSTg7XabjOWwDs\&first share uid=34386458\&share user mpuuid $=858547578 \mathrm{bc}$ 77a613cd323d93bbe2727\&share source=timeline.

[40] 赵忠敬, 大蒜制剂, 中国医刊, (1956) 15.

[41] T. Abdullah, A strategic call to utilize Echinacea-garlic in flu-cold seasons, Journal of the National Medical Association, 92 (2000) 48.

[42] S.S. Percival, Aged garlic extract modifies human immunity, The Journal of nutrition, 146 (2016) 433S-436S.

[43] H. Amagase, Clarifying the real bioactive constituents of garlic, The Journal of nutrition, 136 (2006) 716S-725S.

[44] 马成, 蒜片贴穴治感冒, 中国针炎, (1997) 40.

[45] 王涁，徐立浩，张守堂，吕芙蓉，浅谈中药治疗与饮食调节，黑龙江医学， 25 (2001) 927-927. [46] A. Armentia, S. Martín-Armentia, F. Pineda, B. Martín-Armentia, M. Castro, S. Fernández, A. Moro, M. Castillo, Allergic hypersensitivity to garlic and onion in children and adults, Allergologia et immunopathologia, https://doi.org/10.1016/i.aller.2019.06.005(2019). 